How to cite: Demirci, M., Kaya, Y.Z. (2019) Estimation of Keban Dam Reservoir Level in Turkey Using Artificial Neural Network and Support Vector Machines. 2019 "Air and Water - Components of the Environment" Conference Proceedings, Cluj-Napoca, Romania, p. 197-206, DOI: 10.24193/AWC2019_20.

\title{
ESTIMATION OF KEBAN DAM RESERVOIR LEVEL IN TURKEY USING ARTIFICIAL NEURAL NETWORK AND SUPPORT VECTOR MACHINES
}

\author{
Mustafa DEMIRCI ${ }^{I}$ 凹, Yunus Ziya KAYA ${ }^{2}$
}

DOI: 10.24193/AWC2019_20

\begin{abstract}
The correct estimation of the water level in a reservoir is crucial to optimizing the management of water resources. In this study, Artificial Neural Network (ANN) and Support Vector Machines (SVM) methods were used to estimate the level change of the dam reservoir. Keban Dam located in the Eastern Anatolia region of Turkey was selected as the application area and 731 daily observed data was used.
\end{abstract}

Keywords: Dam Reservoir Level, Estimation, Artificial Neural Network, Support Vector Machines

\section{INTRODUCTION}

The reservoir is the most important and effective water storage facility that changes the distribution of water in time and space. Not only does water provide hydropower and irrigation, it also smoothest extreme flows to mitigate floods or droughts. The optimal operation of the reservoirs in a system is of course very important so that the available water can be used in the best possible way. Reservoir work requires a series of decisions that determine the accumulation and release of water over time. Future estimates of reservoir flow can help deliver effective business decisions. These estimates not only optimize the management of water resources, but also to ensure the safety of a reservoir. The first studies on reservoir capacity determination were carried out by Ripple (1883), Hazen (1914), and Sudler (1927). Artificial intelligence was applied to dam reservoir level, dam reservoir volume, evaporation and in many different disciplines-areas by many researchers (Unes et al. 2013, 2017a, 2017b,2018a, 2018b, 2018c; Demirci and Baltaci 2013, Demirci et al. 2015a, 2015b,2016,2017,2018a,2018b; Tasar et al. 2017; Kaya et al. 2018). Üneş (2010a), tried to determine the Tahtakopru dam level changes with ANN. Campolo et al. (1999) and Imrie et al. (2000) show that ANN can be used in river flow estimates. Sudheer and Jain (2004) tried to explain the intrinsic behavior of artificial neural networks with river flow models. Sudheer (2005) tried to construct river models with information

\footnotetext{
1 Iskenderun Technical University, Eng. Faculty, Civil Eng Department, TURKEY mustafa.demirci@iste.edu.tr

2 Osmaniye Korkut Ata University, Eng. Faculty, Civil Eng Department, TURKEY yunuszkaya@osmaniye.edu.tr
} 
extracted from trained neural networks. Unes (2010b) predicted that the flow of density in the reservoir would reduce the depth depth by using ANN technique. Unes et al (2015a, 2015b) used ANN and GRNN models for estimating the dam reservoir level.

Support vector machines (SVM), which were introduced by Vapnik (1995), are a relatively new structure in the data-driven prediction field. The SVM is based on the structural risk minimization (SRM), instead of the empirical risk minimization (ERM) of ANNs, which can cause the solution to be captured in a local minimum and the network over fitted. The SRM minimizes the empirical error and model complexity simultaneously, which can improve the generalization ability of the SVM for classification or regression problems in many disciplines. Many researchers used SVM method to predict groundwater level (Yoon et al. (2011). and lake water level (Asefa et all. 2005), Khalil et al (2006), Khan and Coulibaly (2006).

In this study, Artificial Neural Network (ANN) and Support Vector Machines (SVM) methods were used to estimate the daily reservoir water level by using daily water consumption, daily evaporation and daily energy demand, lagged time daily reservoir level. Model results were also compared with each other.

\section{DATA AND METHODS}

\subsection{Study Area}

Keban Dam reservoir is the largest artificial lake in Turkey, after Ataturk Dam lake. (Fig. 1). It is ranked 4th after Van Lake, Salt Lake and Atatürk Dam Lake when it is put together with natural lakes. Concrete weight and rock-fill type dam's body volume is $16679000 \mathrm{~m}^{3}$, the height from the river bed $210 \mathrm{~m}$, the lake volume at normal water elevation $31000 \mathrm{hm}^{3}$ the lake area at normal water elevation is 675 $\mathrm{km}^{2}$. The length of the dam along the Murat River Valley is $125 \mathrm{~km}$. Keban dam reservoirs are used for electricity production as well as water hunting and fish production. Turkey is one of the first big investment in terms of energy. Construction started in 1965. In 1974, the first four large tribunes, in 1981, four other turbines entered the circuit. The total installed capacity of the dam is 1330 Megawatt and the annual energy production is 6 Billion $\mathrm{kWh}$. The dam site is located $45 \mathrm{~km}$ northwest of Elazig, $65 \mathrm{~km}$ north-east of Malatya and $10 \mathrm{~km}$ further downstream from the junction of Karasu and Murat. The average amount of water passing is $635 \mathrm{~m}^{3} / \mathrm{sec}$. The average flow rate in winter is between 200 and $300 \mathrm{~m}^{3} / \mathrm{sec} .70 \%$ of the water that the river spends in one year passes between the months of March and June during the snow melting season. (DSI, http://www.dsi.gov.tr/projeler/kebanbaraj\%C4\%B1).

In this study, 731 data for two years were used. Daily reservoir level was estimated by using the daily energy demand of the Keban dam, the daily water consumption, the daily evaporation, reservoir level $(t+1)$. In ANN and SVM models, 511 data of 731 data were used for training and 220 data were used. The results obtained with the model are compared with the measured values. 


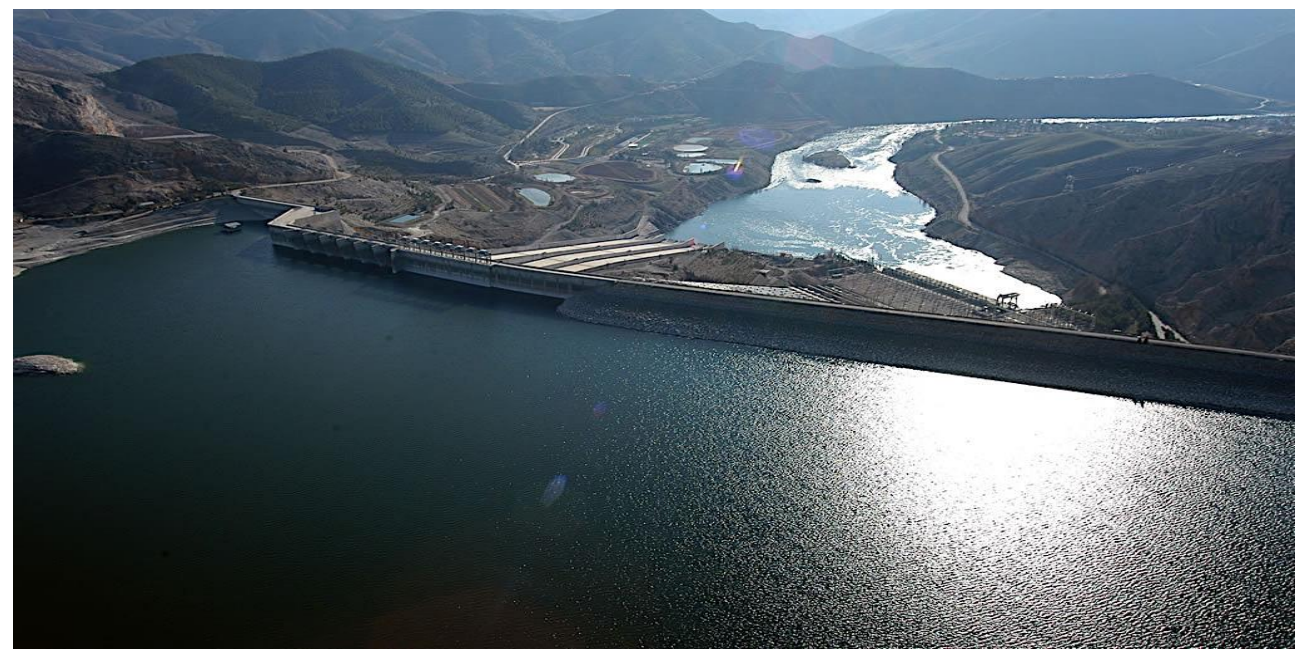

Fig. 1. General view of Keban dam (DSI, http://www.dsi.gov.tr/projeler/kebanbaraj\%C4\%B1)

\subsection{Methods}

\subsubsection{Artificial neural networks (ANN)}

Artificial neural networks (ANN) takes the working structure of human brain as a model and simulates it in its own internal algorithm. Figure 2 shows the threelayer and feed-forward ANN architecture. The data flow in this architecture is unidirectional. The data collected for the study will be included as an input in the ANN model and thus the analysis starts.

If the data in the input layer is called $\mathrm{Xi}$, there is output value $\mathrm{Jn},(\mathrm{n}=1,2,3, \ldots \mathrm{m})$ in output nodes up to $\mathrm{Xi}=(\mathrm{i}=1,2,3, \ldots \mathrm{k})$. These input values are multiplied by Wij $(\mathrm{J}$ $=1,2,3, \ldots \mathrm{h}$ ) in hidden layers and the output values are edited and used as input values of hidden layers. The information in the hidden layer is processed and transmitted to the output layer. In the output layer, the output value is determined and the results are produced and the process is completed.

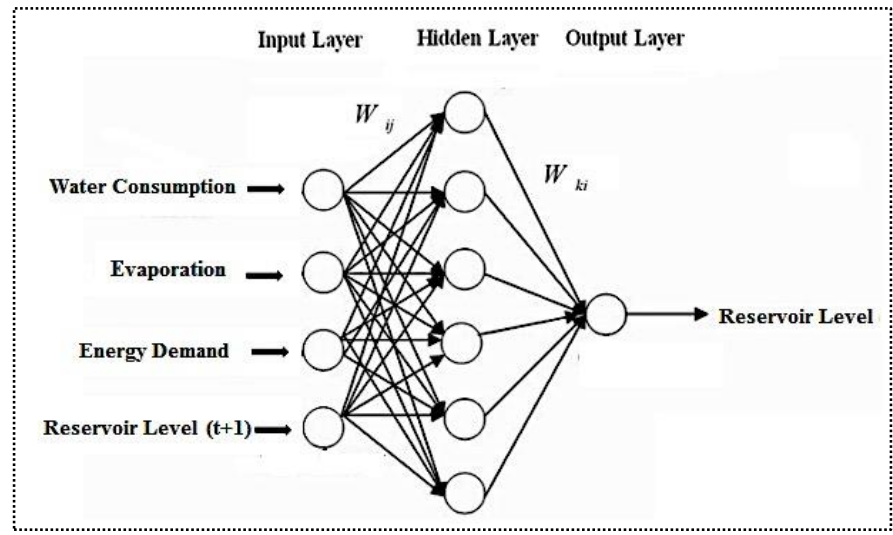

Fig. 1. Location of "La Fontenille" pond 


\subsubsection{Support Vector Machine (SVM)}

Support vector (SVM) is machine-learning approach in data-driven research fields which founded by Cortes and Vapnik (1995). SVM are mainly used to best distinguish between two classes of data. For this purpose, the decision limits or hyper planes are determined. In a non-linear dataset, SVMs cannot draw a linear hyper-plane. Therefore, kernel tricks are used. The Kernel method greatly increases machine learning in nonlinear data. The process of an SVR estimator (y) can be expressed as:

$$
\mathrm{y}=\left(\mathrm{K}_{\mathrm{xi}} \cdot \mathrm{W}_{\mathrm{jk}}\right)+\mathrm{b}
$$

where

$$
\text { the Kernel function is Kpi, }
$$

$\mathrm{b}$ is bias term of SVM network and

$\mathrm{Wjk}$ is called as the weight vector.

$\mathrm{Kx}$ and $\mathrm{W}$ show Lagrange multipliers. Kxi is a nonlinear function that maps the input vectors into a high-dimensional feature space. The inner product of the inputs is calculated by using kernel functions. Lagrange multipliers show the weights. The output value for a sample in the SVR is equal to the sum of the inner product of the inputs and the independent combinations of Lagrange multipliers. The non-linear Kernel functions used in this study are Poly kernel and radial basis function kernels. Details about SVM can be found in Vapnik (1995), Haykin (1999), Vapnik (1999).

\section{RESULTS AND DISCUSSIONS}

\subsection{ANN Results}

ANN model was employed for dam reservoir level prediction. For Artificial Neural Networks (ANN), daily evaporation, daily water consumption, daily energy demand, lagged time reservoir level was used as input values. In this study, a hidden layer MLP (Multilayer sensor) was chosen to define the dam reservoir level problem in ANN. The most common learning method of MLP, the Backpropagation Algorithm (BPA), was used for the input and output data sets. The forward feed Bayesian regularization propagation algorithm was applied with the Marquardt Levenberg Method and written in MATLAB code. In order to develop the dam reservoir models, ANN was trained by using the first data set, in other words the training data consisting of the first 511 day observations. ANN distribution and scatter graphs are shown for testing data in Fig. 3. and Fig. 4. The correlation coefficient was obtained as $\mathrm{R}=0.986$ from the generated graphic. In distribution and scatter charts, ANN values are close to the actual values.

\subsection{SVM Results}

Daily evaporation, water consumption, evaporation, energy demang and lagged time reservoir level were used as input values for predictions reservoir level in Support Vector Machines (SVM) model. SVM distribution and scatter graphs are shown for testing data in Fig. 5. and Fig. 6. The correlation coefficient $R=0.985$ was obtained for the graph generated for the test (Figure 6). The SVM predictions at the test phase has quite good performance. 


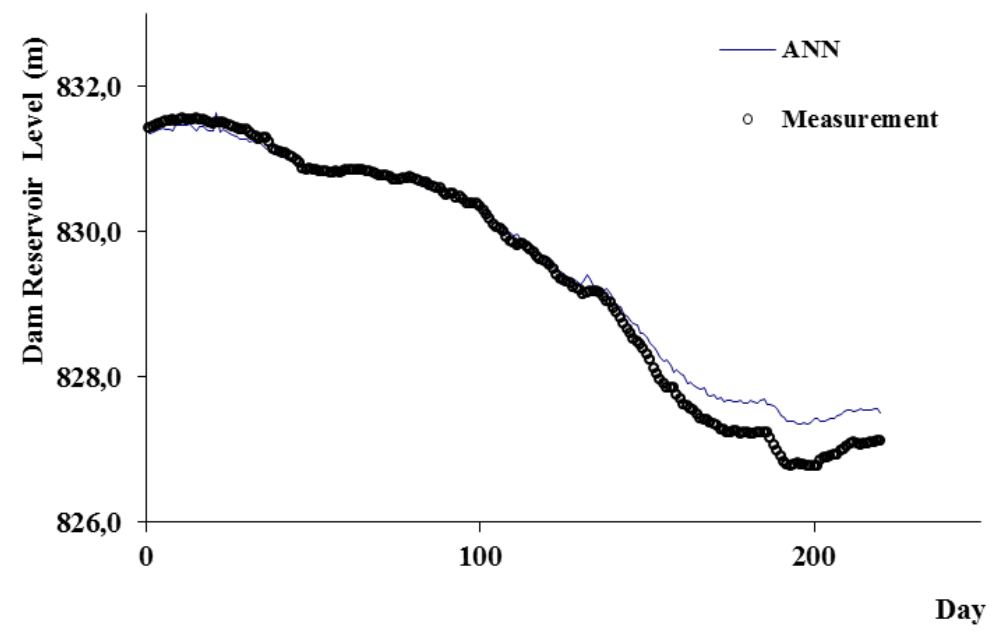

Fig. 3. Measurement and ANN distribution graph for test data

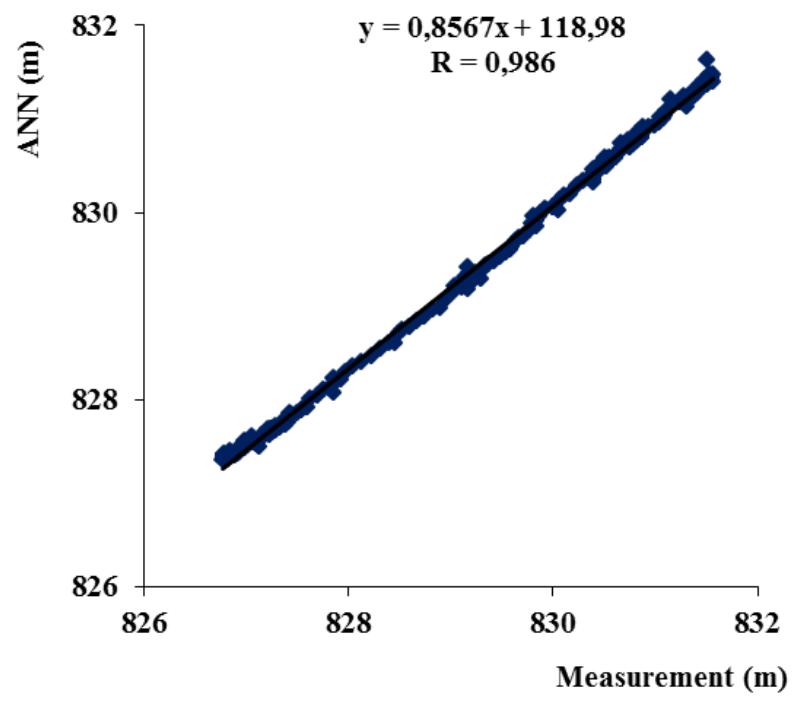

Fig. 4. Measurement and ANN scatter graph for test data

\subsection{General Evaluation}

The correlation coefficient (R), the mean square error (MSE) and the mean absolute error (MAE) were calculated for the performance evaluation of the ANN and SVM models. The results are also used to compare the performance of model estimations and observations. MSE and MAE were determined as follows: 


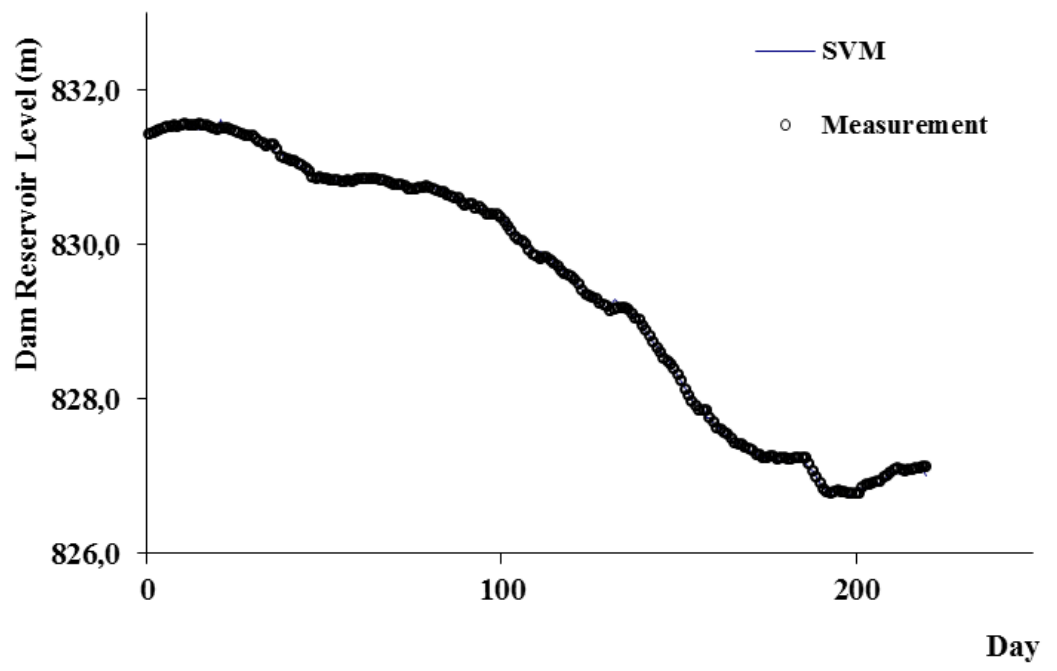

Fig. 5. Measurement and SVM distribution graph for test data

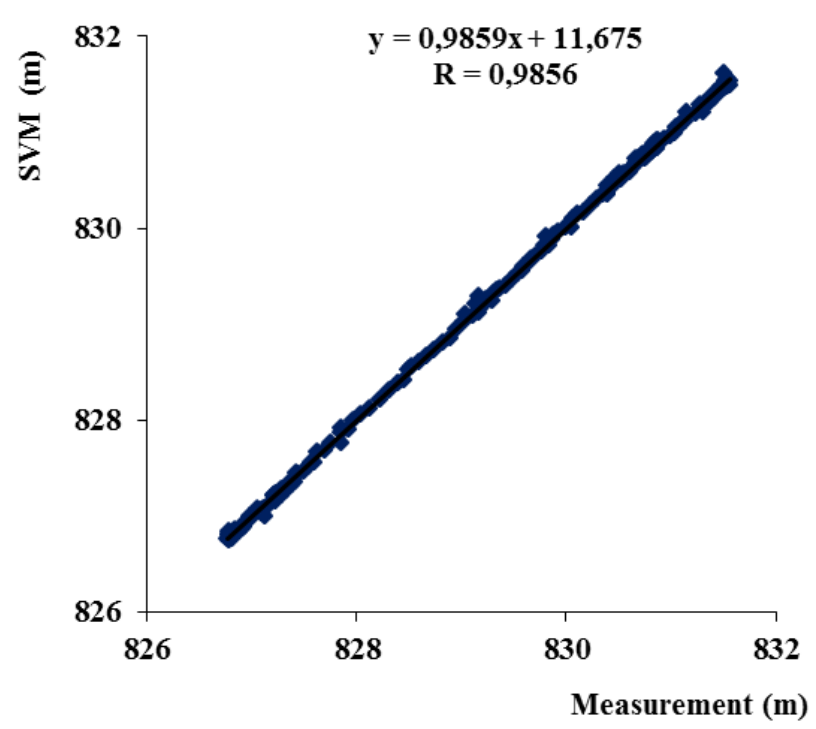

Fig. 6. Measurement and SVM scatter graph for test data

$M S E=\frac{1}{N} *\left(\sum_{i=1}^{N} Y i_{\text {measurement }}-Y i_{\text {prediction }}\right)^{2}$

and

$M A E=\frac{1}{N} * \sum_{i=1}^{N}\left|Y i_{\text {measurement }}-Y i_{\text {prediction }}\right|$

where $\quad \mathrm{N}$ is the number of data and

Yi is the Daily reservoir levels. 
Comparisons of the MSE, MAE and R parameters obtained from the test data are shown in Table 1.

Table 1. Performance of ANN and SVM models

\begin{tabular}{|c|c|c|c|}
\hline Model & MSE & MAE & R \\
\hline ANN & 0,22 & 0,40 & 0,986 \\
\hline SVM & 0,13 & 0,17 & 0,985 \\
\hline
\end{tabular}

MSE: Mean squared error, MAE: Absolute mean error, R: Correlation coefficient

According to the statistical comparison it is seen that SVM method gives better results than ANN model because error calculations belong to SVM model prediction has smaller values than ANN.

\section{CONCLUSION}

In this study, Keban Dam reservoir level was tried to be estimated by using daily reservoir level, total daily water consumption, energy demand and total evaporation. ANN and SVM models were used to estimate the dam reservoir level. It is possible to derive the following results for this study.

The ANN model has yielded results similar to the SVM model in the case of dam reservoir level change. Generally, the ANN model and SVM method give better results in parameters that have no linear relationship between them. In this study, both data driven techniques performance are investigated and it is seen that, both methods show acceptable performance. But SVM method performance is a bit more better than ANN model because of error results. The results of the case study are satisfactory and demonstrate that ANN and SVM models can be a useful prediction tool in the area of dam reservoir level prediction.

\section{REFERENCES}

1. Asefa, T., Kemblowski, M., Lall, U., Urroz G., (2005), Support vector machines for nonlinear state space reconstruction: application to the Great Salt Lake time series, Water Resour. Res., http://dx.doi.org/10.1029/2004WR003785

2. Campolo, M., Andreussi, P., Soldati, A., (1999). River flood forecasting wiht a neural network model. Water Resour. Res. 35(4), 1191-1197.

3. Cortes, C., \& Vapnik, V. (1995). Support-vector networks. Machine learning, 20(3), 273-297

4. Demirci, M., Baltaci, A. (2013). Prediction of suspended sediment in river using fuzzy logic and multilinear regression approaches. Neural Computing and Applications, 23(1), 145-151.

5. Demirci, M., Üneş, F., Saydemir, S. (2015a). Suspended sediment estimation using an artificial intelligence approach. Sediment Matters, Springer, 83-95. 
6. Demirci, M., Üneş, F., Aköz, M. S. (2015b). Prediction of cross-shore sandbar volumes using neural network approach. Journal of Marine Science and Technology, 20(1), 171-179.

7. Demirci, M., Unes, F., Akoz, M. S. (2016). Determination of nearshore sandbar crest depth using neural network approach. International Journal of Advanced Engineering Research and Science, 3(12), 133-140.

8. Demirci M., Unes F., Kaya Y.Z., Mamak M., Tasar B., Ispir E. (2017), Estimation of Groundwater Level Using Artificial Neural Networks: A Case Study of Hatay-Turkey. 10th International Conference "Environmental Engineering".

9. Demirci, M., Tasar B., Kaya, Y.Z, Varcin, H. (2018a). Estimation of Groundwater Level Fluctuations Using Neuro-Fuzzy and Support Vector Regression Models. International Journal of Advanced Engineering Research and Science, 5(12), 206-212.

10. Demirci M., Unes F., Kaya Y.Z., Tasar B., Varcin H. (2018b), Modeling of Dam Reservoir Volume Using Adaptive Neuro Fuzzy Method. Air and Water Components of the Environment Conference, DOI: 10.24193/AWC2018_18

11.DSI, (Turkish General of State Hydraulic Works), http://www.dsi.gov.tr/projeler/keban-baraj\%C4\%B1

12. Haykin, S. (1999). Multilayer perceptrons. Neural networks: a comprehensive foundation, 2, 135-155.

13. Hazen, A., (1914), Storage to be provided in the impounding reservoirs for municipal water supply: Transactions of the American Society of Civil Engineers 77, 15471550.

14. Imrie, C.E., Durucan, S., Kore, A. (2000) River flow prediction using artificial neural networks: generalization beyond the calibration range. Journal of Hydrology 233, 138-153

15. Kaya Y.Z., Unes F., Demirci M., Tasar B., Varcin H. (2018), Groundwater Level Prediction Using Artificial Neural Network and M5 Tree Models. Air and Water Components of the Environment Conference, DOI: 10.24193/AWC2018_23

16. Khalil, A.F. McKee M., Kemblowski M., Asefa, T. Bastidas, L., (2006), Multiobjective analysis of chaotic dynamic systems with sparse learning machines, Adv. Water Resour. 29 72-88.

17. Khan M.S., Coulibaly P., (2006) Application of support vector machine in lake water level prediction, J. Hydrol. Eng., 11 199-205

18. Ripple, W. (1883). The Capacity of Storage for water supply, Proc., Institution of Civil Engineers, 71, 270.

19. Sudler, C. E., (1927), Storage Required for Regulation of Streamflow, Trans., ASCE, 91, No. 622.

20. Sudheer, K.P., Jain A., (2004). Explaining the internal behaviour of artificial neural network river flow models. Hydrological Processes 18 (4): 833-844.

21. Sudheer K.P., (2005). Knowledge extraction from trained neural network river flow models, Journal of Hydrologic Engineering 10 (4): 264-269.

22. Taşar, B., Kaya, Y. Z., Varçin, H., Üneş, F., Demirci, M. (2017). Forecasting of suspended sediment in rivers using artificial neural networks approach. International Journal of Advanced Engineering Research and Science, 4(12), 79-84.

23. Üneş, F.(2010a), Dam reservoir level modelıng by neural network approach. A case study, Neural Network World 4, 461- 474.

24. Üneş, F. (2010b). Prediction of density flow plunging depth in dam reservoir: An artificial neural network approach. Clean - Soil, Air, Water 38, 296 - 308. 
25. Unes, F., Yildirim, S., Cigizoglu, HK., \& Coskun, H. (2013). Estimation of dam reservoir volume fluctuations using artificial neural network and support vector regression. Journal of Engineering Research, 1(3), 53-74.

26. Üneş, F., Demirci, M., Kişi, Ö., (2015a), Prediction of millers ferry dam reservoir level in USA using artificial neural network, Periodica Polytechnica Civil Engineering 59, 309-318.

27. Üneş, F. and Demirci, M. (2015b). Generalized Regression Neural Networks For Reservoir Level Modeling. International Journal of Advanced Computational Engineering and Networking, 3, 81-84.

28. Unes, F., Gumuscan, F. G., Demirci, M. (2017a). Prediction of Dam Reservoir Volume Fluctuations Using Adaptive Neuro Fuzzy Approach. EJENS, 2(1), 144-148.

29. Unes F., Kaya Y.Z., Mamak M., Demirci M. (2017b), Evapotranspiration Estimation Using Support Vector Machines and Hargreaves-Samani Equation for St. Johns, FL, USA. 10th International Conference" Environmental Engineering", Doi: 10.3846/enviro.2017.094

30. Unes, F., Boluk O, Kaya, YZ, Tasar B., Varcin, H. (2018a), Estimation of RainfallRunoff Relationship Using Artificial Neural Network Models for Muskegon Basin. International Journal of Advanced Engineering Research and Science, 5(12), 198-205.

31. Üneş F., Doğan S., Taşar B., Kaya Y., Demirci M. (2018b), The Evaluation and Comparison of Daily Reference Evapotranspiration with ANN and Empirical Methods. Natural and Engineering Sciences, 3(3), Supplement, 54-64.

32. Üneş F., Demirci M., Mertcan Z., Taşar B., Varçin H., Ziya Y. (2018c). Determination of Groundwater Level Fluctuations by Artificial Neural Networks. Natural and Engineering Sciences, 3(3), Supplement, 35-42.

33. Vapnik, V.N., (1995). The Nature of Statistical Learning Theory. Springer-Verlag, New York, USA.

34. Vapnik, V. N. (1999). An overview of statistical learning theory. IEEE transactions on neural networks, 10(5), 988-999.

35. Yoon, H., Jun, S. C., Hyun, Y. Bae, G.O., Lee K. K., (2011). A comparative study of artificial neural networks and support vector machines for predicting groundwater levels in a coastal aquifer, Journal of Hydrology, 396, 128-138. 
